\title{
Risk Factors for Childhood Leukemia: Radiation and Beyond
}

\author{
Janine-Alison Schmidt ${ }^{1 *}$, Sabine Hornhardt ${ }^{1}$, Friederike Erdmann ${ }^{2,3}$, \\ Isidro Sánchez-García ${ }^{4}$, Ute Fischer ${ }^{5}$, Joachim Schüz ${ }^{3}$ and Gunde Ziegelberger ${ }^{1}$
}

${ }^{1}$ Department of Effects and Risks of lonizing and Non-ionizing Radiation, Federal Office for Radiation Protection (BfS), Neuherberg, Germany, ${ }^{2}$ Division of Childhood Cancer Epidemiology, Institute of Medical Biostatistics, Epidemiology and Informatics (IMBEI), University Medical Center of the Johannes Gutenberg University Mainz, Mainz, Germany, ${ }^{3}$ Environment and Lifestyle Epidemiology Branch, International Agency for Research on Cancer, World Health Organization (IARC/WHO), Lyon, France, ${ }^{4}$ Experimental Therapeutics and Translational Oncology Program, Instituto de Biología Molecular y Celular del Cáncer, CS/C/Universidad de Salamanca, Salamanca, Spain, ${ }^{5}$ Department of Pediatric Oncology, Hematology and Clinical Immunology, Medical Faculty, Heinrich Heine University, Düsseldorf, Germany

OPEN ACCESS

Edited by:

Manuela Marron,

Leibniz Institute for Prevention

Research and Epidemiology

(LG), Germany

Reviewed by:

Danuta Januszkiewicz-Lewandowska, Poznan University of Medical

Sciences, Poland

Maike Wolters,

Leibniz Institute for Prevention

Research and Epidemiology

(LG), Germany

Kevin Y. Urayama

St. Luke's International

University, Japan

*Correspondence:

Janine-Alison Schmidt jschmidt@bfs.de

Specialty section: This article was submitted to

Children and Health,

a section of the journa

Frontiers in Public Health

Received: 30 October 2021 Accepted: 06 December 2021 Published: 24 December 2021

Citation:

Schmidt J-A, Hornhardt S, Erdmann F, Sánchez-García I, Fischer U, Schüz J and Ziegelberger G (2021) Risk

Factors for Childhood Leukemia:

Radiation and Beyond.

Front. Public Health 9:805757. doi: 10.3389/fpubh.2021.805757
Childhood leukemia $(\mathrm{CL})$ is undoubtedly caused by a multifactorial process with genetic as well as environmental factors playing a role. But in spite of several efforts in a variety of scientific fields, the causes of the disease and the interplay of possible risk factors are still poorly understood. To push forward the research on the causes of $\mathrm{CL}$, the German Federal Office for Radiation Protection has been organizing recurring international workshops since 2008 every two to three years. In November 2019 the 6th International Workshop on the Causes of CL was held in Freising and brought together experts from diverse disciplines. The workshop was divided into two main parts focusing on genetic and environmental risk factors, respectively. Two additional special sessions addressed the influence of natural background radiation on the risk of $\mathrm{CL}$ and the progress in the development of mouse models used for experimental studies on acute lymphoblastic leukemia, the most common form of leukemia worldwide. The workshop presentations highlighted the role of infections as environmental risk factor for $\mathrm{CL}$, specifically for acute lymphoblastic leukemia. Major support comes from two mouse models, the Pax $5^{+/-}$and Sca1-ETV6-RUNX1 mouse model, one of the major achievements made in the last years. Mice of both predisposed models only develop leukemia when exposed to common infections. These results emphasize the impact of gene-environment-interactions on the development of $\mathrm{CL}$ and warrant further investigation of such interactions - especially because genetic predisposition is detected with increasing frequency in $\mathrm{CL}$. This article summarizes the workshop presentations and discusses the results in the context of the international literature.

Keywords: magnetic fields, genetic susceptibility, environmental exposure, acute lymphoblastic leukemia, childhood leukemia, risk factors, radiation

\section{INTRODUCTION}

Leukemia is the most frequent cancer in children, with a proportion of about $30 \%$ of all cancers diagnosed in children before the age of 15 years (1). The most common form, lymphoid leukemia, makes up one fourth of all cancers. Almost $98 \%$ of childhood lymphoid leukemias are precursor cell leukemias with precursor B-cell acute lymphoblastic leukemia (pB-ALL) being the most 
common form (1). Over the past decades, advances in diagnostics, risk grouping, pharmacology, and treatment combinations have led to remarkable enhancements in treatment of and survival from childhood leukemia (CL), with an overall survival for acute lymphoblastic leukemia (ALL) exceeding $90 \%$ in high-income countries nowadays (2). However, knowledge of the complex causes of the disease that may help implementing preventative measures, is still lacking. A growing body of research has targeted a wide range of potential risk factors for childhood ALL, including genetic and environmental ones (3). Environmental risk factors, as defined in this review, include exposure to environmental pollutants, such as air pollution, life style factors, such as parental tobacco smoking or alcohol consumption, microorganisms and viruses, and natural as well as man-made exposures like radiation. Two observations in particular attracted the attention of the German Federal Office for Radiation Protection (Bundesamt für Strahlenschutz, BfS): a moderately increased risk of CL (including ALL) from exposure to extremely low-frequency magnetic fields (ELF-MF) (4), like from power lines, and an increased incidence of CL (including ALL) near German nuclear power plants (NPPs) (5). Both findings are difficult to explain given the current knowledge of the biological mechanisms. Non-ionizing radiation deposits too little energy in cellular DNA and other likely targets to be considered directly causative. While ionizing radiation is an established cause of CL, exposures in the vicinity of NPPs are too low to recognize a direct causal relationship. Motivated by these observations the BfS set up a research agenda and corresponding research recommendations on the basis of two international workshops held in 2008 and 2010 that brought together an interdisciplinary group of experts (6). The research recommendations were last updated on a third workshop in 2012 (7), and two follow-up meetings were organized subsequently in 2016 and 2019. In some research areas the increasing research efforts made some particular progress and new results appear to answer at least some of the open questions that were addressed in the research recommendations set up in 2012. This article summarizes the latest evidence and new findings that were presented at the 2019 International Workshop on the Causes of CL held in Freising, embedded in a discussion in the context of the international literature.

\section{INCIDENCE AND TIME TRENDS}

In 2018, the International Agency for Research on Cancer (IARC) in collaboration with the International Association of Cancer Registries (IACR) coordinated a huge effort to assess the most recent incidence of childhood cancer worldwide based on quality-assured data collected from cancer registries: International Incidence of Childhood Cancer volume 3 (IICC-3), which is at the present time the most comprehensive and most up-to date source of data on global childhood cancer incidence $(8,9)$. Results of IICC-3 and a comparison of the data with incidence rates from 1980s were presented at the workshop. The IICC-3 study included data from 2001-2010 on cancer in children and adolescents diagnosed before 20 years of age in populations covered by cancer registries that met predefined data quality criteria. Leukemia was the most common cancer worldwide representing $36.1 \%$ of all cases in children aged 014 years and $15.4 \%$ in adolescents aged 15-19 years (8). The latest internationally comparable data on incidence patterns of childhood cancer have been published in IICC-2 in 1998 (10) covering (approximately) the decade of the 1980's. Regarding all childhood cancers combined, the assessment of time trends in the incidence rates between the two time periods, 1980's and 2001-2010, revealed an overall increase in registered childhood neoplasms, from 124.0 to 140.6 per million person-years since the 1980's. The increase was seen worldwide except for the subSaharan Africa region, where in fact a decrease in registered childhood cancers was observed. Looking specifically on time trends for lymphoid leukemia, a similar picture was evident with increasing incidence rates across regions. The increase was particularly pronounced in sub-Saharan Africa (in contrast to the decrease in all childhood cancers combined) and North Africa where the age-standardized incidence rates had doubled. An increase in lymphoid leukemias was also seen in South, Southeast, and West Asia as well as in Eastern Europe, albeit less pronounced (11). Improvement in diagnosis and registration might likely explain some of the increase of incidence rates since the 1980's. Notably, the IICC-2 and IICC-3 studies were restricted to cases diagnosed and treated within the national health care system, naturally missing undetected cases and those without a verified diagnosis (12). Major under-ascertainment in cancer registries was identified for childhood cancer, particularly in low- but also middle-income countries, because a significant fraction of suspected cases never reaches complete diagnosis and treatment. The latter is mainly due to related costs or lack of infrastructure (12). This is why two independent studies projecting the more realistic true childhood cancer incidence came up with numbers $70-80 \%$ higher than those collected by the cancer registries $(13,14)$. CL appeared to be among the childhood cancer types even more underestimated than many solid cancers with more visible symptoms (15).

At this stage, it is impossible to disentangle the different factors contributing to geographical differences and differences in time trends. Completeness of ascertainment is certainly a major factor. However, it might also reflect differences in susceptibility to leukemia in different racial or ethnic groups as seen in the IICC-3 data, where the highest leukemia rates in the USA were seen in White Hispanic children whereas it was less common in US Black children (8). Exposure to environmental factors may also differ between low-, middle- and high-income countries. To solve these issues global research efforts are essential.

\section{GENETIC RISK FACTORS}

\section{Preleukemic Clones}

pB-ALL shows several biologically distinct subtypes defined by chromosomal alterations of which the most frequent are aneuploidy and chromosomal translocations (16). Strong evidence for a prenatal origin of aneuploidy and of several chromosomal translocations came from studies of concordant leukemia in monozygotic twins and from screening of Guthrie 
cards (17-19). Subsequent studies examined if the most frequent translocation that leads to the formation of the ETV6-RUNX1 fusion gene can also be found in healthy newborns. These studies were summarized and discussed at the workshop. Using cord blood samples from healthy newborns the presence of ETV6-RUNX1 gene fusions was previously revealed in around $1-2 \%$ of samples employing RNA as a specimen and RNAbased detection methods such as RT-PCR (20-23). Using a novel detection method called GIPFEL ("Genomic inverse PCR for exploration of ligated breakpoints") that utilizes DNA as starting material (24), Schäfer et al. (25) found a frequency of 5\% for the ETV6-RUNX1 fusion gene in cord blood of healthy newborns in a Danish cohort. The use of a more reliable DNA-based approach, instead of the previously used RNA-based approaches, is a likely cause for the different results regarding ETV6-RUNX1 frequency in newborns (26). Recently, the TCF3-PBX1 fusion, present in around $5-10 \%$ of B-ALL patients and assumed to arise postnatally, has been detected in $0.6 \%$ of umbilical cord blood samples of healthy newborns by GIPFEL, confirming that this translocation can likewise occur prenatally (27).

The frequency of fusion genes in healthy newborns exceeds by large ( $\geq 100$ times) the incidence of the corresponding leukemia subtypes and might still be underestimated because the detection rate of GIPFEL is $<100 \%(24,27)$. An alternative explanation for this high frequency of fusion genes in healthy newborns might be that the ETV6-RUNX1 fusion gene detected in healthy individuals is only present in non-self-renewing differentiated cells, and not in hematopoietic stem cells or early progenitors, which are known to be more capable of developing malignant clones (28). Therefore, second hits are clearly needed for progression of these preleukemic clones into full-blown leukemia. However, it is currently not known how much the frequency of the ETV6-RUNX1 fusion genes differs across infant populations around the world, and future studies have to show how the presence and frequency of preleukemic clones in blood at birth affects the risk of the newborn for developing ALL later in life. Revealing the changes caused by chromosomal translocations, such as ETV6-RUNX1, and leading to progression of the disease, could then potentially allow to prevent $\mathrm{pB}$-ALL development in preleukemic carriers (29).

\section{Inherited Genetic Susceptibility}

The current state of knowledge on inherited genetic susceptibilities was summarized in a talk making clear that germline predisposition is more and more recognized as an important risk factor for the development of childhood ALL (30). Genome-wide association studies have identified susceptibility loci in ARID5B, CEBPE, BMI1, CDKN2A/2B and others that are associated with an increased risk to develop childhood ALL [for a summary see (31)]. Some of these are more frequently associated with certain racial and/or ethnic groups; e.g., ARID5B is more frequently found in Hispanics (32) and might be a possible explanation for the higher incidence rates seen in this ethnic group (see section Incidence and Time Trends). Rare germline mutations in developmental hematopoietic genes, like ETV6, PAX5 or IKZF1, have also been shown to predispose children to ALL (30). Rare syndromes, like Cornelia de Lange and Rubinstein-Taybi syndrome that have been associated with childhood ALL, further point to a connection between variants in cohesin complex genes and CREBBP/EP300 pathway, respectively, and ALL susceptibility $(33,34)$. Other syndromes connected to a higher risk of ALL and AML include Down syndrome (35), Noonan syndrome (36), constitutional mismatch repair deficiency syndrome (37), Fanconi anemia, and others summarized in $(30,38)$. The total prevalence of pathogenic germline mutations in known cancer predisposing genes in children and adolescents with leukemia is $4.4 \%$, but this is probably only the tip of the iceberg (39). Novel techniques used for testing for hereditary cancer predisposition syndromes (CPSs), in particular whole-exome sequencing of parent-child trios, lead to the discovery of new germline risk variants (40-42). Trio sequencing can also identify new inheritance patterns in children with cancer where the family history is unremarkable and does not point to an underlying CPS. This is the case with a so called digenic inheritance pattern, when two germline variants in two different genes are needed for causing the clinical cancer phenotype. One mutation is inherited by each of the unaffected parent, or, alternatively, one occurs $d e$ novo (43). Thus, such di- or oligogenic inheritance patterns could be accountable for a substantial number of childhood cancers (44). The use of trio sequencing can therefore give important insights into the mutational landscape of CPSs as well as into the mechanisms of cancer development in children (43). Expanding this knowledge is a crucial step toward targeted treatments as well as precision-prevention programs (42). Nevertheless, testing for CPSs can provoke emotional and relational challenges in the families in addition to the distress of the child's cancer diagnosis and treatment (45).

\section{Epigenetics}

Global epigenetic changes are a hallmark of cancer, and genetic as well as metabolic and environmental stimuli can cause such changes $(46,47)$. As epigenetic modifications are also characteristic for childhood ALL (48), one session focused specifically on this topic. A summary of the evidence of epigenetic priming in cancer cells was presented. Epigenetic priming is based on the suggestion made by several studies that oncogenic lesions in human cancers contribute to cancer development by (epi-)genetically modifying the cancer-initiating cell but are dispensable for tumor progression $(49,50)$. In hematologic malignancies such epigenetic reprogramming has been linked to hematopoietic stem/progenitor cells $(51,52)$. The epigenetic modifications are preserved throughout tumor development, even if the oncogene is no longer present or expressed, and may remain latent until triggered by either endogenous or environmental stimuli (49). These stimuli, or second hits, can arise randomly. However, the epigenetically primed cell may also be more sensitive to a certain environmental exposure that will favor the emergence of a second hit. In other cases, exposure to an environmental factor could cause epigenetic changes that increase the susceptibility for secondary genetic alterations. This is described as a gene-environmentinteraction (49). A good example is pB-ALL. Here it was assumed that, e.g., the frequent chimeric transcription factor 
ETV6-RUNX1 epigenetically primes an uncommitted cell subset thereby inducing an aberrant B cell differentiation program that is later on susceptible to transformation (53). Evidence for this came from a transgenic ETV6-RUNX1 mouse model, described in more detail in section 'Epidemiological Evidence for an Infection-Mediated Childhood Leukemogenesis', where predisposed mice only developed leukemia after exposure to infections (54).

Inducing DNA methylation changes may also be a mechanism of action for at least some of the environmental risk factors that have been associated with CL (see section Environmental Risk Factors). For example, given the current knowledge of the mechanism of action of ELF-MF, this type of exposure cannot damage the DNA directly but might induce epigenetic changes that could affect the child's risk for CL later in life (55). Several large-scale epigenome-wide association studies have reported associations of relevant maternal exposures during pregnancy, including tobacco smoking, air pollution, and body mass index, with DNA methylation in offspring neonatal blood. For instance, decreased methylation at arylhydrocarbon receptor repressor (AHRR) CpG cg05575921 has been associated with exposure to maternal smoking during pregnancy (57). Such methylation changes could affect health later in life (56). If this would be the case for ALL, common DNA methylation changes should be associated with both a given exposure and leukemia. This hypothesis, formulated and investigated by Timms et al. (58) using a "meet in the middle" approach, was discussed at the workshop. Briefly, genome wide DNA methylation changes after exposure to environmental risk factors associated with $\mathrm{CL}$ were compared to ALL-specific methylation changes. Overlapping gene loci were found for several risk-associated exposures, including maternal radiation exposure, alcohol intake, sugary caffeinated drink intake during pregnancy, and smoking. For radiation exposure, alcohol intake, sugary caffeinated drinks, and attended day nursery, more than $70 \%$ of the gene loci that overlapped with ALL-specific gene loci also had the same direction of methylation change, i.e. were hypo- or hypermethylated (58).

Investigating DNA methylation changes in response to environmental risk factors seems to be an appealing method for studying the contribution and mechanism of action of these factors in promoting disease development (59). Using epigenetic biomarkers for maternal smoking during pregnancy, i.e., DNA methylation at $A H R R$ and a recently established polyepigenetic smoking score, two recent studies provided evidence that prenatal tobacco smoke exposure was associated with a higher frequency of somatic gene deletions among childhood B-ALL cases $(60,61)$. However, these results are inconsistent to epidemiological findings because those studies did not show an association between maternal smoking and childhood ALL risk (62). Epidemiological evidence for other parental exposures, like maternal caffeine intake or alcohol intake, is likewise inconsistent (55). More studies are therefore needed to understand the induction of epigenetic changes by environmental exposures and especially their contribution to CL development.

\section{ENVIRONMENTAL RISK FACTORS}

\section{Infections}

In the context of infections and leukemia there are two hypotheses that have to be mentioned shortly. The first one is the "population mixing" hypothesis by Kinlen (63). The second one is Greaves "delayed infection" hypothesis (64). Both hypotheses propose that ALL is a consequence of an abnormal response to common infections. Currently, three additional models of ALL evolution exist, which also point to infection-induced immune disturbances as being responsible for leukemia evolution as recently summarized by Hauer et al. (65). A more detailed view into the role of infections is given elsewhere $(17,66,67)$.

\section{Epidemiological Evidence for an Infection-Mediated Childhood Leukemogenesis}

Indications for an infectious etiology of CL came from observations of leukemia cases occurring in closer spatial and temporal proximity than would be expected if they occurred independent from one another. The first systematic review and pooled analysis of such space-time clustering studies was presented and discussed at the workshop. This study showed strong evidence of clustering of $\mathrm{CL}$ at time of diagnosis for children aged $0-5$ years, an age range including the peak incidence for leukemia at 2-4 years (68). Results were similar for ALL. Such clustering in space and time could be explained by "mini-epidemics" of a single infection leading to local clusters of leukemia cases (68), which are observed from time to time (69-72). For children aged 5 to 15 years no clustering at both birth and diagnosis was observed, and results for lymphoma and CNS tumors provided only weak evidence for space-time clustering (68). Nevertheless, the systematic review was restricted to studies using a certain methodology only and there have been other approaches showing no evidence for clustering, e.g., in Germany $(73,74)$. Studies on population mixing showed evidence for an excess risk of $C L$ in studies of extreme population mixing rather than in studies with modest one (75). On balance, there is some evidence for clustering but it is not fully understood to what extent and under which circumstances it occurs.

A critical time window for infections and risk of leukemia is not only postnatally in early childhood but includes also the time during pregnancy. Maternal infections during pregnancy have long been studied as potential risk factors for CL and the epidemiological evidence was lastly summarized by Maia Rda and Wünsch Filho in 2013 in a narrative review (76). Only recently, $\mathrm{He}$ et al. (77) published the first systematic review and meta-analysis on this topic including 15 studies on ALL and 14 on CL and the results were discussed at the workshop. The most frequently studied infection variables for ALL as well as CL were viral or virus-associated infections, followed by systemic symptoms (e.g., urinary tract infection), bacterial infections, and fungal infections. Most of the studies reported a positive association of CL and ALL with infection. When looking for specific types of infection a higher risk for ALL was associated with influenza infections, whereas $\mathrm{CL}$ in general was 
associated with influenza, rubella, and varicella infections during pregnancy. Nevertheless, the authors report high heterogeneity across the studies and an insufficient number of studies, which is why the results should be handled with caution. A major limitation relates to the self-reported information assessed years after the pregnancy that most studies rely on (77). The same group very recently published a pooled analysis of six populationbased birth cohorts using prospective data (78). Birth cohorts are less prone to recall and selection bias than case-control studies that were predominantly included in the previous meta-analysis. Results of the pooled analysis showed a higher risk for any leukemia (including ALL) in association with maternal urinary tract infections as well as respiratory tract infections during pregnancy; in contrast to the meta-analysis that did not find such an association. The association with influenza infections was again observed but the effect size was lower compared to the meta-analysis (78).

\section{Experimental Evidence for an Infection-Mediated Childhood Leukemogenesis}

Experimental evidence that infections promote pB-ALL development comes from a new $\mathrm{pB}$-ALL mouse model that was presented in a special session on mouse models (see also section Experimental Findings): Transgenic Sca1-ETV6-RUNX1 mice only developed pB-ALL when exposed to common pathogens (conventional facility, CF conditions) but not when kept in a specific pathogen-free (SPF) environment (54). In the Sca1ETV6-RUNX1 mouse model, human ETV6-RUNX1 is expressed within hematopoietic stem/progenitor cells thereby mimicking human ETV6-RUNX1 preleukemic biology. After exposure to an infectious environment these mice show a significant increase in pro/pre-B cells, although differentiation to mature peripheral blood B-cells is not impaired. Furthermore, when housed under CF conditions, these mice showed a distinct expression pattern, compared with healthy age-matched wild type mice, with significantly higher expression of recombination activating gene 1 (Rag1) and Rag2 and differential regulation of epigenetic regulator genes of the lysine demethlyase (KDM) family (54). Similar observations were made with the Pax5 heterozygous knock out mouse model where mice only developed pB-ALL under CF conditions (79). Susceptibility to infections in $\mathrm{Pax}^{+/-}$mice was suggested to be due to a higher sensitivity of $\mathrm{Pax}^{+/-}$pro-B cells to interleukin 7 (IL-7) withdrawal, favoring the accumulation of secondary Jak3 mutations as a rescue mechanism in these mice $(54,79)$.

It has been suggested that infections trigger pB-ALL development by induction of the mutagenic enzyme activationinduced cytidine deaminase (AID), which is normally involved in producing antibody diversity. AID may promote secondary genetic changes in preleukemic B-cell precursor cells but evidence for this view mainly came from ex vivo studies $(80,81)$. To overcome this restriction, the role of AID was examined in crossed $\mathrm{Pax}^{+/-}$mice by a gain- and loss-of-function experiment, respectively (80). The presented results of this study clearly showed that genetic deletion of AID does not affect the latency and penetrance of $\mathrm{pB}-\mathrm{ALL}$ and premature expression of AID in earliest pro-B-cell stages does not promote $\mathrm{pB}-\mathrm{ALL}$ development. Additionally, AID expression was not observed in preleukemic precursor B-cells of Sca1-ETV6-RUNX1 or Pax $5^{+/-}$ mice held in SPF or CF conditions, respectively. These results confirm that infectious stimuli can promote malignant B-cell leukemogenesis through AID-independent mechanisms (80).

Another talk provided new hints that might explain how genetic predispositions affect the susceptibility to infections and in turn promote leukemia. This involves namely the gut microbiome which was shown to differ between $\mathrm{Pax} 5^{+/-}$mice and WT mice under SPF and CF housing conditions (82). It is well known that microbes colonizing the gastrointestinal tract are integral in shaping the development and function of the immune system and alterations in the composition of the microbiota have been linked with several human diseases (83). To determine its role in $\mathrm{pB}$-ALL development, the gut microbiome of $\mathrm{Pax}^{+/-}$mice was depleted with antibiotics by a short-term treatment (for 8 weeks) starting when mice reached adulthood. When kept constantly under SPF conditions, i.e. without an infectious stimulus, $50 \%$ of treated $\mathrm{Pax}^{+/-}$mice developed pB-ALL whereas untreated mice did not. It was further shown that the composition of the gut microbiome varied between Pax $5^{+/-}$mice, which stayed healthy, and $P a x 5^{+/-}$mice, which developed leukemia, but a specific microbe connected with the development of pB-ALL could not be identified. The observation that predisposed mice with a depleted gut microbiota developed leukemia, even without infectious stimuli, suggests that an intact gut microbiome protects genetically predisposed mice from developing $\mathrm{pB}$-ALL (82). This protective effect is likely mediated through the release of microbial components or metabolites, or direct microbial binding to Toll-like receptors on innate immune cells $(65,67)$.

Further insights into how infections could promote leukemia development came from a presented co-culture study of murine ETV6-RUNX1-positive $\mathrm{Ba} / \mathrm{F} 3$ pro-B cells and bone-marrow mesenchymal stromal cells (BM-MSCs). In a competitive growth assay, ETV6-RUNX1-positive and control Ba/F3 cells were mixed and plated on murine BM-MSCs with or without IL-6/IL$1 \beta /$ tumor necrosis factor-alpha pro-inflammatory cytokines, which are normally secreted by pathogen receptors expressing cells in response to several types of infections (84). This mesenchymal inflammatory environment or "niche" favored the emergence of ETV6-RUNX1-positive Ba/F3 clones by differentially affecting their proliferation and survival. Moreover, this inflammatory niche preferentially attracted ETV6-RUNX1positive $\mathrm{Ba} / \mathrm{F} 3$ clones through the CXCR2 receptor and increased the extent of DNA double strand breaks as judged by the levels of histone AX phosphorylation $(\gamma \mathrm{H} 2 \mathrm{AX})$, thereby providing a chance for transformation of the pre-leukemic clone (84).

Taken together, the role of infections as risk factor in the etiology of ALL, specifically pB-ALL, has strengthened considerably since the last research recommendations in 2014 (7), with the strongest support coming from the Pax $5^{+/-}$and Sca1ETV6-RUNX1 mouse models. Therefore, training the immune system early in life could potentially help to prevent leukemia development and several epidemiological studies demonstrate that proxies for infectious agents or immune challenges early in life reduce the risk of ALL (65). Questions remain to be clarified 
regarding the time window in which infections are relevant, the specific infectious pathogen or pathogens that are involved (if any single given microbe could in fact be responsible) as well as the mechanism(s) and pathway(s) by which infections drive - or protect against - ALL development. The ongoing coronavirus disease 2019 (COVID-19) pandemic is affording an opportunity to answer some of the open questions, and is putting Greaves delayed infection hypothesis to the proof: Children all over the world did not encounter SARS-Cov-2 (severe acute respiratory syndrome coronavirus type 2) before, and the lockdown measures might have led to far fewer encounters with pathogens in infancy than usual (85). In the next years, it should be thoroughly investigated if this will lead to a higher risk of ALL in children who experienced lockdown measures.

\section{lonizing Radiation}

High and moderate doses of IR have been well recognized as environmental risk factor for CL for several decades. Exposure during young ages seems to be particularly critical, as study findings are consistent with a higher risk of radiation-induced cancer after exposure during childhood, compared to exposure later in life (86-90). The dose response for leukemia after IR exposure is described as linear-quadratic, slowly changing at low doses, but rapidly at high doses (91). So far, generally, the linear no-threshold model for radiation effects is widely accepted by national and international bodies for assessing the risks resulting from exposures to IR (92), but this means that effects in the low dose range - defined as doses $<100 \mathrm{mGy}$ absorbed dose (93) - are often extrapolated. This is also true for leukemia models. This low dose range is most relevant for the general population. However, low-dose studies are a challenge due to the need of large cohorts and high individual variation. Therefore, evidence for leukemia in the range of low doses is still sparse. Strongest support for the risk of CL comes from pooled analyses from exposure for diagnostic or therapeutic reason. Cumulative active bone marrow (ABM) doses between 100 and $20 \mathrm{mSv}$ (effective dose) in childhood/adolescence increased the risk significantly (94). A recent study of six pooled studies assessing cancer risks associated with computed tomography (CT) with available ABM between 5.9 and $10.1 \mathrm{mGy}$ found a significant increased risk for CL (95). To date, no increased risk was found for single X-ray examinations $(95,96)$.

Sources of low doses of IR not only include exposure by medical radiation but also man-made environmental exposure (e.g., nuclear weapons testing). Attention was drawn on several statistical associations of CL in the vicinity of nuclear installations. On a previous workshop in 2012, the consistent findings and trends in European studies about CL risk near NPPs were discussed in the context of previous findings, leukemia etiology, and other risk factors (7). It was concluded that there was no elevated risk of CL globally near NPPs in children $<15$ years old. However, there might be some elevated risk of CL when considering the $0-4$-year age category within $5 \mathrm{~km}$ from a NPP, even though the associations were not statistically significant. Recent data from Belgium could link the leukemia risk of young children only to one specific site (97).
By far the greatest contribution to exposure received by the general world population comes from natural background radiation (NBR) (98). Numerous epidemiological studies investigated the association of NBR exposure (including radon and gamma radiation exposure) and cancer risk (including $\mathrm{CL}$ ), but results are mostly inconsistent (99). In a special workshop session dedicated to NBR, a recent study from Switzerland was discussed that used data from a census-based cohort study to check for an association between cancer in children $<16$ years of age and exposure to terrestrial gamma and cosmic radiation. The study found evidence of associations for leukemia and CNS tumors with a hazard ratio of about 1.04 per $\mathrm{mSv}$ cumulative whole-body dose for both groups (100). However, biases due to inaccurate exposure assessment could not be excluded and statistical power was limited due to small sample sizes. A very recent study considered more accurate measurements of terrestrial radiation based on a new map of terrestrial radiation in Switzerland and an extended cohort. The authors confirmed the recent results that NBR contributes to the risk of leukemia in children (101). However, studies in France do not support an association between NBR and a higher risk of childhood acute leukemia (including ALL and AML) $(102,103)$.

Another talk of the special session on NBR discussed the results of a registry-based case-control study undertaken in Great Britain. This study found an excess relative risk for CL of 1.12 per $\mathrm{mSv}$ of cumulative red-bone-marrow dose from gamma radiation, but results for CL and radon and other childhood cancers were not significant (104). The main shortcoming of this study was the lack of individual dose assessment. As a consequence, about half of the cases and controls had the same dose-rate estimates because these were based on the mean gamma ray doses of their birth registration district. To overcome these limitations, a new study is ongoing which includes a larger number of cases and controls using an extended calendar period and an extended set of indoor gamma-ray measurements from the United Kingdom Childhood Cancer Study [UKCCS (105)]. For a better estimation of indoor gamma ray dose rates, several ad hoc models were explored and the results were published (106108).

Some of the most recent studies have been summarized by Mazzei-Abba et al. (99) in 2019 and their review includes a comprehensive discussion about methodological differences, limitations, and challenges that have to be faced when evaluating the findings of these studies. They point out that larger study populations or pooled studies are needed to investigate cytogenetic subgroups of diseases, while the main challenge is to accurately assess children's individual exposure to NBR. In the latest review, Kendall et al. (109) conclude that at present no firm conclusions about NBR and childhood cancer can be reliably drawn.

\section{Extremely Low-Frequency Magnetic Fields (ELF-MF) Epidemiological Findings}

Until today, more than 40 epidemiological studies examined the relationship between ELF-MF and the risk of CL, including five 
pooled studies since the year $2000(4,110-113)$. A brief summary and discussion of these epidemiological findings was given in a talk. The presented study results are relatively consistent in that they show a higher risk for developing CL and specifically ALL with MF exposures above 0.3 or $0.4 \mu \mathrm{T}$. Based on these findings, IARC classified ELF-MF as possibly carcinogenic to humans (Group 2B) in the year 2002 (114). However, how ELF-MF may cause leukemia is unknown - until today, no plausible biological mechanism has been found, and experimental in vitro and in vivo studies do not confirm the results of the epidemiological studies. Besides, it was shown that newer epidemiological findings point to a decline in the reported relative risk (RR) since the 1990's to now (115): In their analysis, Swanson et al. (115) calculated the cumulative RR from 32 studies published up to each successive calendar year, showing that the RR settled around 2 in the mid1990 s before declining to a current value of 1.44 in 2017, though the decline is not statistically significant. Improvement of study quality was not considered an explanation for the decline by the authors. Other possible explanations for the observed decline could be a true causal risk that declined over time, as discussed by the authors, or a confounder that was present in earlier years but is not present any longer; however, such explanations would need further investigation. In a pooled analysis of the four most recently published studies, no association was observed between ELF-MF and CL (116). Combining those with results from two previous pooled analyses from Kheifets et al. (111) and Ahlbom et al. (4), attenuates the association at $>0.4 \mu \mathrm{T}$ to an odds ratio of 1.45 (95\% CI: 0.95-2.20) (116). It should be pointed out that epidemiological studies on the association of ELF-MF and CL usually report on total leukemia cases and/or the ALL subtype but do not distinguish between the cytogenetic subgroups of the disease. This is due to the very small numbers of exposed cases even in the pooled analyses, but cytogenetic subgroups might display different susceptibilities to ELF-MF. Another problem faced by most epidemiological studies is the extremely low number of cases in the highest exposure category because only few children are exposed to $\mathrm{MF} \geq 0.2 \mu \mathrm{T}$ (117). In case-control studies, however, the key concern is selection bias. It was shown that non-participating controls tend to have a lower socio-economic status, which is related to higher ELFMF exposure (118). This might have led to an overestimation of the association of the potential effect of ELF-MF on CL incidence in studies requiring subject participation (119).

\section{Experimental Findings}

Previous hazard identification and risk assessments by IARC, the World Health Organization (WHO), and the Scientific Committee on Emerging and Newly Identified Health Risks (SCENIHR) considered evidence from experimental animal studies on the association of ELF-MF and leukemia as inadequate $(114,120,121)$, and such studies have been hampered by the fact that no animal model existed that resembled the human disease appropriately. Therefore, different mouse models and their applicability in CL research were discussed in a special session of the workshop. Presented mouse models included the Cdkn2a deficient/ETV6-RUNX1 mouse model, the PAX5-ELN mouse model, and the Sca1-ETV6-RUNX1 mouse model already described in section Experimental Evidence for an InfectionMediated Childhood Leukemogenesis, Cdkn2a deficient/ETV6RUNX1 as well as PAX5-ELN transgenic mice developed neoplasms with a high incidence of up to $50-80 \%$, respectively $(122,123)$. In case of the Cdkn2a deficient/ETV6-RUNX1 mouse model also neoplasms other than B-cell lymphomas/leukemias were developed. The Sca1-ETV6-RUNX1 mouse model was developed and tested specifically for usefulness in ELF-MF research during the EU-funded project Advanced Research on Interaction Mechanisms of electroMagnetic exposures with Organisms for Risk Assessment (ARIMMORA). As it considers the two-hit model of leukemogenesis and also shows a low penetrance, this model is most applicable to test the contribution of potential environmental risk factors as second hits. One ARIMMORA pilot project used this mouse model for studying the effect of $1.5 \mathrm{mT}$ ELF-MF exposure on hematopoietic compartments of the peripheral blood in a SPF environment. A small but significant decrease in $\mathrm{CD}^{+} \mathrm{T}$ lymphocytes was seen in exposed mice at 2 months of age (124). Similarly, in another ARIMMORA project, CD1 mice exposed to $10 \mu \mathrm{T}, 1 \mathrm{mT}$ and $10 \mathrm{mT}$ ELF-MF, respectively, showed a decrease in CD8 ${ }^{+}$ $\mathrm{T}$ lymphocytes at 4 weeks of age in all exposed groups (125). If this early decrease is of any functional relevance has yet to be ascertained. Of special interest is the observation of pB-ALL development in one out of 30 Sca1-ETV6-RUNX1 mice during the course of the above mentioned ARIMMORA pilot project (124). This finding was not statistically significant because of the small numbers of animals and it is unclear if it is connected to the decrease in $\mathrm{CD}^{+} \mathrm{T}$ lymphocytes - cells that are known mediators of anti-tumor immunity and can recognize and eliminate tumor cells (126). Future experiments with much larger animal numbers are clearly needed to validate these findings and to clarify the role of ELF-MF in the development of ALL.

\section{Other Environmental Factors}

There are quite a number of environmental factors for leukemia that have been investigated in epidemiological studies besides IR and ELF-MF and that were not specifically addressed at the workshop [for a more detailed overview see review by Schüz and Erdmann (127)]. Among the recognized risk factors are high and low birth weight (128) and sex, with boys more often affected than girls (129). Pesticide exposure $(130,131)$, air pollution (132-134), paint (135), paternal tobacco smoking $(136,137)$, and prelabour cesarean delivery (138) have been associated with an increased risk for ALL or AML but to date none of them is regarded as an established risk factor. There are also some factors that have been associated with a reduced risk for leukemia in the child, including maternal supplementation with folic acid or vitamins (139), or breastfeeding (140). Two consortia, the Childhood Leukemia International Consortium (CLIC) and the International Childhood Cancer Cohort Consortium (I4C), are putting much effort into clarifying the relevance of the environmental risk factors in question. Nevertheless, the child's risk to develop CL can be modified by genetic susceptibility, and novel predisposition syndromes are being reported constantly. One hypothesis states that the first oncogenic hit primes the cell through epigenetic modification and such preleukemic cells could be more sensitive to environmental risk factors 


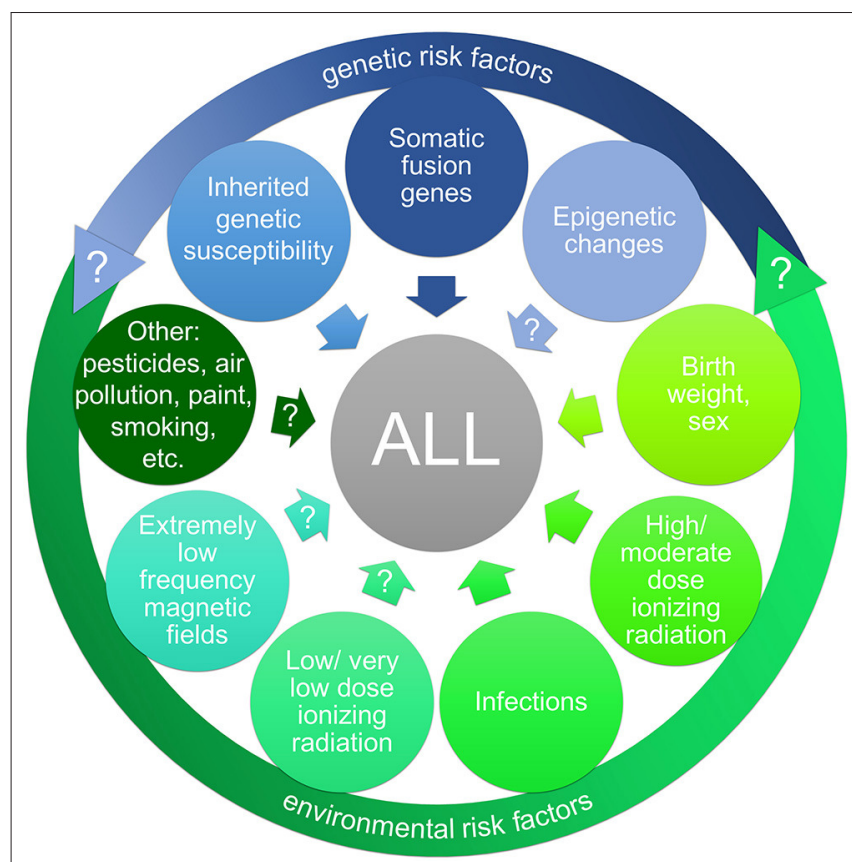

FIGURE 1 | Risk factors (potential and established) for childhood acute lymphoblastic leukemia (ALL). A large body of research has targeted a wide range of possible risk factors for childhood $A L L$, including genetic risk factors (indicated in blue) and environmental risk factors (indicated in green). The interaction of genetic and environmental risk factors

(gene-environment-interaction) may have an impact on ALL development. Inherited genetic susceptibility is detected with increasing frequency in childhood leukemia as well as preleukemic fusion genes as predisposing factors. The impact of epigenetic alterations (possibly induced by oncogenes or environmental exposures) on ALL development is yet unclear. Among the recognized environmental risk factors are high and low birth weight and sex as well as high to moderate doses of ionizing radiation. The relevance of infections as risk factor for ALL has strengthened considerably in the last decade. In contrast, evidence for an association between a higher risk for ALL and exposure to low/very low doses of ionizing radiation, extremely low frequency magnetic fields (e.g., from power lines), and other environmental risk factors (like pesticides or air pollution), respectively, has yet to be verified.

(49). Therefore, a multidisciplinary approach is needed in the future that considers this likely association between genetic and environmental risk factors.

\section{DISCUSSION}

Research efforts on the causes of CL have made some progress in the past years (Figure 1). Due to new screening methods, like GIPFEL and trio sequencing, genetic predisposition is detected with increasing frequency in CL. Whereas inherited or de novo germline CPS are rare but highly penetrant, the presence of a somatically acquired fusion gene, like ETV6RUNX1, or of a germline susceptibility locus confers only a very low or reduced disease penetrance. Regarding environmental risk factors, birth weight, sex and high to moderate doses of IR are among the recognized ones. Despite a growing body of research, results for an association between other environmental risk factors (including environmental pollutants and parental life style factors) and a higher risk for CL are largely inconsistent and overall inconclusive. One noticeable exception are infections, as evidence of a causal relationship with CL has strengthened considerably in the last years. Not only epidemiological analyses underline an association between maternal infections during pregnancy and a higher risk for CL in the offspring (77, 78). Especially two predisposed mouse models, $P a \times 5^{+/-}$and Sca1-ETV6-RUNX1, highlighted the role of infections in the development of pB-ALL $(54,79,82)$. Mice of both genotypes only develop leukemia in conjunction with exposure to common pathogens and closely resemble human $\mathrm{pB}-\mathrm{ALL}$ in penetrance, pathology, and genomic lesions $(29,79)$. These models further underscore the role of gene-environment-interactions in this disease. Such interactions may also occur through epigenetic changes induced by the environmental exposure and leading to the reprogramming of the cancer cell of origin (49). These mouse models can now be used to investigate whether and how environmental exposures other than infections affect leukemia development in vivo, as biological evidence is sparse. Especially in the case of ELF-MF, experimental studies are clearly needed to validate if the consistent epidemiological observation of an increased leukemia risk is real, and to identify a possible biological mechanism that could explain these findings. One promising approach may be to look for epigenetic changes after exposure to ELF-MF, as this is regarded as a potential mediating mechanism between environmental risk factors and CL.

Many other questions still remain unanswered, starting with the basic one of whether and how much geographical variation in the true incidence rates of CL there really is. Notably, within high-income countries, the incidence rates of CL vary substantially less than lifestyle- and environmentallyrelated cancers in adults. A multidisciplinary and global approach will be needed to bring together the existing evidence from epidemiological, experimental and mechanistic studies, to improve exposure assessment and consistency between countries, and for a better understanding of the incidence and distribution of CL worldwide. The Global Acute Leukemia network (GALnet ${ }^{1}$ ), initiated in 2010 by the BfS and coordinated by IARC, has already established an international network for a multidisciplinary study of $\mathrm{CL}$, and together with the work of CLIC and I4C these international associations will hopefully provide new insights into this most common type of childhood cancer worldwide.

\section{AUTHOR CONTRIBUTIONS}

J-AS, GZ, SH, and JS were part of the organizing committee of the workshop. J-AS wrote the first draft of the manuscript. $\mathrm{SH}, \mathrm{FE}$, IS-G, UF, JS, and GZ contributed to the revision of the initial draft of the manuscript. All authors read and approved the final manuscript.

\section{FUNDING}

The Federal Ministry for the Environment, Nature Conservation and Nuclear Safety Germany funded the international workshop (3619I02454). Open access publication

\footnotetext{
${ }^{1}$ https://galnet.iarc.fr
} 
fees were funded by the German Federal Office for Radiation Protection.

\section{ACKNOWLEDGMENTS}

We would like to thank all the participants of the 6th International Workshop on the Causes of CL for their substantial

\section{REFERENCES}

1. Erdmann F, Kaatsch P, Grabow D, Spix C. German Childhood Cancer Registry - Annual Report 2019 (1980-2018). Mainz: Institute of Medical Biostatistics, Epidemiology and Informatics (IMBEI) at the University Medical Center of the Johannes Gutenberg University Mainz (2020).

2. Erdmann F, Frederiksen LE, Bonaventure A, Mader L, Hasle H, Robison LL, et al. Childhood cancer: survival, treatment modalities, late effects and improvements over time. Cancer Epidemiol. (2021) 71(Pt B):101733. doi: 10.1016/j.canep.2020.101733

3. Ziegelberger G, Dehos A, Grosche B, Hornhardt S, Jung T, Weiss W. Childhood leukemia-risk factors and the need for an interdisciplinary research agenda. Prog Biophys Mol Biol. (2011) 107:312-4. doi: 10.1016/j.pbiomolbio.2011.09.010

4. Ahlbom A, Day N, Feychting M, Roman E, Skinner J, Dockerty J, et al. A pooled analysis of magnetic fields and childhood leukaemia. Br J Cancer. (2000) 83:692-8. doi: 10.1054/bjoc.2000.1376

5. Kaatsch P, Spix C, Schulze-Rath R, Schmiedel S, Blettner M. Leukaemia in young children living in the vicinity of German nuclear power plants. Int $J$ Cancer. (2008) 122:721-6. doi: 10.1002/ijc.23330

6. Ziegelberger G, Baum C, Borkhardt A, Cobaleda C, Dasenbrock C, Dehos A, et al. Research recommendations toward a better understanding of the causes of childhood leukemia. Blood Cancer J. (2011) 1:e1. doi: 10.1038/bcj.2010.1

7. Laurier D, Grosche B, Auvinen A, Clavel J, Cobaleda C, Dehos A, et al. Childhood leukaemia risks: from unexplained findings near nuclear installations to recommendations for future research. J Radiol Prot. (2014) 34:R53-68. doi: 10.1088/0952-4746/34/3/R53

8. Steliarova-Foucher E, Colombet M, Ries LAG, Moreno F, Dolya A, Bray F, et al. International incidence of childhood cancer, 200110: a population-based registry study. Lancet Oncol. (2017) 18:71931. doi: 10.1016/S1470-2045(17)30186-9

9. International Agency for Research on Cancer. (2019). International Incidence of Childhood Cancer 3. Available online at: https://iicc.iarc.fr/index.php (accessed November 24, 2021).

10. Parkin DM, Kramarova E, Draper GJ, Masuyer E, Michaelis J, Neglia J, et al. International Incidence of Childhood Cancer. Lyon: International Agency for Research on Cancer (1998).

11. Erdmann F, Colombet M, Moreno F, Schuz J, Stiller C, Steliarova-Foucher E. Variations and trends in incidence of lymphoid leukaemia in children: results from 131 population-based cancer registries around the globe - on behalf of IICC-3 contributors. 51st Congress of the International Society of Paediatric Oncology (SIOP); 2019 Oct 23-26; Lyon. Pediatr Blood Cancer. (2019) 66:e27989. doi: 10.1002/pbc.27989

12. Schuz J, Roman E. Childhood cancer: a global perspective. Cancer Epidemiol. (2021) 71(Pt B):101878. doi: 10.1016/j.canep.2020.101878

13. Johnston WT, Erdmann F, Newton R, Steliarova-Foucher E, Schuz J, Roman E. Childhood cancer: estimating regional and global incidence. Cancer Epidemiol. (2021) 71(Pt B):101662. doi: 10.1016/j.canep.2019.101662

14. Ward ZJ, Yeh JM, Bhakta N, Frazier AL, Atun R. Estimating the total incidence of global childhood cancer: a simulation-based analysis. Lancet Oncol. (2019) 20:483-93. doi: 10.1016/S1470-2045(18)30909-4

15. Erdmann F, Kielkowski D, Schonfeld SJ, Kellett P, Stanulla M, Dickens C, et al. Childhood cancer incidence patterns by race, sex and age for 2000-2006: a report from the South African National Cancer Registry. Int J Cancer. (2015) 136:2628-39. doi: $10.1002 / \mathrm{ijc} .29308$ contributions, helpful comments and their valid inputs to a fruitful discussion. Especially we would like to thank Ximena Vergara and Ben Spycher for organizing the special sessions on animal models and natural background radiation, respectively, and we would like to thank Arndt Borkhardt for his contribution as part of the organizing committee and his suggestions on the manuscript.
16. Mullighan CG. Molecular genetics of B-precursor acute lymphoblastic leukemia. J Clin Invest. (2012) 122:3407-15. doi: 10.1172/JCI61203

17. Greaves MA. causal mechanism for childhood acute lymphoblastic leukaemia. Nat Rev Cancer. (2018) 18:47184. doi: $10.1038 / s 41568-018-0015-6$

18. Maia AT, Tussiwand R, Cazzaniga G, Rebulla P, Colman S, Biondi A, et al. Identification of preleukemic precursors of hyperdiploid acute lymphoblastic leukemia in cord blood. Genes Chromosomes Cancer. (2004) 40:38-43. doi: 10.1002/gcc.20010

19. Taub JW, Konrad MA, Ge Y, Naber JM, Scott JS, Matherly LH, et al. High frequency of leukemic clones in newborn screening blood samples of children with B-precursor acute lymphoblastic leukemia. Blood. (2002) 99:2992-6. doi: 10.1182/blood.V99.8.2992

20. Mori H, Colman SM, Xiao Z, Ford AM, Healy LE, Donaldson C, et al. Chromosome translocations and covert leukemic clones are generated during normal fetal development. Proc Natl Acad Sci U S A. (2002) 99:82427. doi: $10.1073 /$ pnas. 112218799

21. Eguchi-Ishimae M, Eguchi M, Ishii E, Miyazaki S, Ueda K, Kamada $\mathrm{N}$, et al. Breakage and fusion of the TEL (ETV6) gene in immature B lymphocytes induced by apoptogenic signals. Blood. (2001) 97:73743. doi: 10.1182/blood.V97.3.737

22. Kosik P, Skorvaga M, Durdik M, Jakl L, Nikitina E, Markova E, et al. Low numbers of pre-leukemic fusion genes are frequently present in umbilical cord blood without affecting DNA damage response. Oncotarget. (2017) 8:35824-34. doi: 10.18632/oncotarget.16211

23. Olsen M, Hjalgrim H, Melbye M, Madsen HO, Schmiegelow K. RT-PCR screening for ETV6-RUNX1-positive clones in cord blood from newborns in the Danish National Birth Cohort. J Pediatr Hematol Oncol. (2012) 34:301-3. doi: 10.1097/MPH.0b013e3182332268

24. Fueller E, Schaefer D, Fischer U, Krell PF, Stanulla M, Borkhardt A, et al. Genomic inverse PCR for exploration of ligated breakpoints (GIPFEL), a new method to detect translocations in leukemia. PLoS ONE. (2014) 9:e104419. doi: 10.1371/journal.pone.0104419

25. Schafer D, Olsen M, Lahnemann D, Stanulla M, Slany R, Schmiegelow $\mathrm{K}$, et al. Five percent of healthy newborns have an ETV6-RUNX1 fusion as revealed by DNA-based GIPFEL screening. Blood. (2018) 131:8216. doi: 10.1182/blood-2017-09-808402

26. Hein D, Borkhardt A, Fischer U. Insights into the prenatal origin of childhood acute lymphoblastic leukemia. Cancer Metastasis Rev. (2020) 39:161-71. doi: 10.1007/s10555-019-09841-1

27. Hein D, Dreisig K, Metzler M, Izraeli S, Schmiegelow K, Borkhardt A, et al. The preleukemic TCF3-PBX1 gene fusion can be generated in utero and is present in approximately $06 \%$ of healthy newborns. Blood. (2019) 134:1355-8. doi: 10.1182/blood.201900 2215

28. Rodriguez-Hernandez G, Casado-Garcia A, Isidro-Hernandez M, Picard D, Raboso-Gallego J, Aleman-Arteaga S, et al. The second oncogenic hit determines the cell fate of ETV6-RUNX1 positive leukemia. Front Cell Dev Biol. (2021) 9:704591. doi: 10.3389/fcell.2021.704591

29. Rodriguez-Hernandez G, Schafer D, Gavilan A, Vicente-Duenas C, Hauer J, Borkhardt A, et al. Modeling the process of childhood ETV6-RUNX1 B-cell leukemias. Oncotarget. (2017) 8:102674-80. doi: 10.18632/oncotarget.21281

30. Bloom M, Maciaszek JL, Clark ME, Pui CH, Nichols KE. Recent advances in genetic predisposition to pediatric acute lymphoblastic leukemia. Expert Rev Hematol. (2020) 13:55-70. doi: 10.1080/17474086.2020.1685866 
31. Klco JM, Mullighan CG. Advances in germline predisposition to acute leukaemias and myeloid neoplasms. Nat Rev Cancer. (2021) 21:12237. doi: 10.1038/s41568-020-00315-Z

32. Xu H, Cheng C, Devidas M, Pei D, Fan Y, Yang W, et al. ARID5B genetic polymorphisms contribute to racial disparities in the incidence and treatment outcome of childhood acute lymphoblastic leukemia. J Clin Oncol. (2012) 30:751-7. doi: 10.1200/JCO.2011.38.0345

33. Fazio G, Massa V, Grioni A, Bystry V, Rigamonti S, Saitta C, et al. First evidence of a paediatric patient with Cornelia de Lange syndrome with acute lymphoblastic leukaemia. J Clin Pathol. (2019) 72:55861. doi: 10.1136/jclinpath-2019-205707

34. Mullighan CG, Zhang J, Kasper LH, Lerach S, Payne-Turner D, Phillips LA, et al. CREBBP mutations in relapsed acute lymphoblastic leukaemia. Nature. (2011) 471:235-9. doi: 10.1038/nature09727

35. Marlow EC, Ducore J, Kwan ML, Cheng SY, Bowles EJA, Greenlee RT, et al. Leukemia risk in a cohort of 3.9 million children with and without down syndrome. J Pediatr. (2021) 234:172-80 e3. doi: 10.1016/j.jpeds.2021.03.001

36. Kratz CP, Franke L, Peters H, Kohlschmidt N, Kazmierczak B, Finckh U, et al. Cancer spectrum and frequency among children with Noonan, Costello, and cardio-facio-cutaneous syndromes. Br J Cancer. (2015) 112:13927. doi: $10.1038 /$ bjc. 2015.75

37. Ripperger T, Schlegelberger B. Acute lymphoblastic leukemia and lymphoma in the context of constitutional mismatch repair deficiency syndrome. Eur J Med Genet. (2016) 59:133-42. doi: 10.1016/j.ejmg.2015.12.014

38. Vagher J, Maese L, Gammon A, Kohlmann W, Schiffman JD. Inherited Risk for Childhood Leukemia. In: Malkin D, editor. The Hereditary Basis of Childhood Cancer. Cham: Springer (2021). p. 315-60. doi: 10.1007/978-3-030-74448-9_11

39. Zhang J, Walsh MF, Wu G, Edmonson MN, Gruber TA, Easton J, et al. Germline mutations in predisposition genes in pediatric cancer. $N$ Engl J Med. (2015) 373:2336-46. doi: 10.1056/NEJMoa1508054

40. Brozou T, Taeubner J, Velleuer E, Dugas M, Wieczorek D, Borkhardt A, et al. Genetic predisposition in children with cancer - affected families' acceptance of Trio-WES. Eur J Pediatr. (2018) 177:53-60. doi: 10.1007/s00431-017-2997-6

41. Wagener R, Taeubner J, Walter C, Yasin L, Alzoubi D, Bartenhagen C, et al. Comprehensive germline-genomic and clinical profiling in 160 unselected children and adolescents with cancer. Eur J Hum Genet. (2021) 29:130111. doi: 10.1038/s41431-021-00878-x

42. Lin $M$, Nebral K, Gertzen CGW, Ganmore I, Haas OA, Bhatia S. et al. JAK2 pG571S in B-cell precursor acute lymphoblastic leukemia: a synergizing germline susceptibility. Leukemia. (2019) 33:2331-5. doi: 10.1038/s41375-019-0459-z

43. Kuhlen M, Borkhardt A. Trio sequencing in pediatric cancer and clinical implications. EMBO Mol Med. (2018) 10:e8641. doi: 10.15252/emmm.201708641

44. Taeubner J, Wieczorek D, Yasin L, Brozou T, Borkhardt A, Kuhlen M. Penetrance and expressivity in inherited cancer predisposing syndromes. Trends Cancer. (2018) 4:718-28. doi: 10.1016/j.trecan.2018.09.002

45. McGill BC, Wakefield CE, Vetsch J, Lim Q, Warby M, Metcalfe A, et al. "I remember how I felt, but I don't remember the gene": Families' experiences of cancer-related genetic testing in childhood. Pediatr Blood Cancer. (2019) 66:e27762. doi: $10.1002 / \mathrm{pbc} .27762$

46. Flavahan WA, Gaskell E, Bernstein BE. Epigenetic plasticity and the hallmarks of cancer. Science. (2017) 357:eaal2380. doi: 10.1126/science.aal2380

47. Sharma S, Kelly TK. Jones PA. Epigenetics in cancer. Carcinogenesis. (2010) 31:27-36. doi: 10.1093/carcin/bgp220

48. Nordlund J, Syvanen AC. Epigenetics in pediatric acute lymphoblastic leukemia. Semin Cancer Biol. (2018) 51:12938. doi: 10.1016/j.semcancer.2017.09.001

49. Vicente-Duenas C, Hauer J, Cobaleda C, Borkhardt A, Sanchez-Garcia I. Epigenetic Priming in Cancer Initiation. Trends Cancer. (2018) 4:40817. doi: 10.1016/j.trecan.2018.04.007

50. Perez-Caro M, Cobaleda C, Gonzalez-Herrero I, Vicente-Duenas C, Bermejo-Rodriguez C, Sanchez-Beato $M$, et al. Cancer induction by restriction of oncogene expression to the stem cell compartment. EMBO J. (2009) 28:8-20. doi: 10.1038/emboj.2008.253
51. Green MR, Vicente-Duenas C, Romero-Camarero I, Long Liu C, Dai B, Gonzalez-Herrero I, et al. Transient expression of Bcl6 is sufficient for oncogenic function and induction of mature B-cell lymphoma. Nat Commun. (2014) 5:3904. doi: 10.1038/ncomms4904

52. Vicente-Duenas C, Gonzalez-Herrero I, Sehgal L, Garcia-Ramirez I, Rodriguez-Hernandez G, Pintado B, et al. Dnmt1 links BCR-ABLp210 to epigenetic tumor stem cell priming in myeloid leukemia. Leukemia. (2019) 33:249-78. doi: 10.1038/s41375-018-0192-Z

53. Raboso-Gallego J, Casado-Garcia A, Isidro-Hernandez M, Vicente-Duenas C. Epigenetic priming in childhood acute lymphoblastic Leukemia. Front Cell Dev Biol. (2019) 7:137. doi: 10.3389/fcell.2019.00137

54. Rodriguez-Hernandez G, Hauer J, Martin-Lorenzo A, Schafer D, Bartenhagen C, Garcia-Ramirez I, et al. Infection exposure promotes ETV6-RUNX1 precursor B-cell Leukemia via Impaired H3K4 Demethylases. Cancer Res. (2017) 77:4365-77. doi: 10.1158/0008-5472.CAN-17-0701

55. Timms JA, Relton CL, Rankin J, Strathdee G, McKay JA. DNA methylation as a potential mediator of environmental risks in the development of childhood acute lymphoblastic leukemia. Epigenomics. (2016) 8:51936. doi: 10.2217/epi-2015-0011

56. Kupers LK, Monnereau C, Sharp GC, Yousefi P, Salas LA, Ghantous A, et al. Meta-analysis of epigenome-wide association studies in neonates reveals widespread differential DNA methylation associated with birthweight. Nat Commun. (2019) 10:1893. doi: 10.1038/s41467-019-09671-3

57. Joubert BR, Felix JF, Yousefi P, Bakulski KM, Just AC, Breton C, et al. DNA Methylation in newborns and maternal smoking in pregnancy: genome-wide consortium meta-analysis. Am J Hum Genet. (2016) 98:68096. doi: 10.1016/j.ajhg.2016.02.019

58. Timms JA, Relton CL, Sharp GC, Rankin J, Strathdee G, McKay JA. Exploring a potential mechanistic role of DNA methylation in the relationship between in utero and post-natal environmental exposures and risk of childhood acute lymphoblastic leukaemia. Int J Cancer. (2019) 145:293343. doi: 10.1002/ijc.32203

59. Potter C, Moorman AV, Relton CL, Ford D, Mathers JC, Strathdee $\mathrm{G}$, et al. Maternal red blood cell folate and infant vitamin B12 status influence methylation of genes associated with childhood acute lymphoblastic leukemia. Mol Nutr Food Res. (2018) 62:e1800411. doi: 10.1002/mnfr.201800411

60. Xu K, Li S, Whitehead TP, Pandey P, Kang AY, Morimoto LM, et al. Epigenetic biomarkers of prenatal tobacco smoke exposure are associated with gene deletions in childhood acute lymphoblastic leukemia. Cancer Epidemiol Biomarkers Prev. (2021) 30:1517-25. doi: 10.1158/1055-9965.EPI-21-0009

61. de Smith AJ, Kaur M, Gonseth S, Endicott A, Selvin S, Zhang L, et al. Correlates of prenatal and early-life tobacco smoke exposure and frequency of common gene deletions in childhood acute lymphoblastic leukemia. Cancer Res. (2017) 77:1674-83. doi: 10.1158/0008-5472.CAN-16-2571

62. Chunxia D, Meifang W, Jianhua Z, Ruijuan Z, Xiue L, Zhuanzhen Z, et al. Tobacco smoke exposure and the risk of childhood acute lymphoblastic leukemia and acute myeloid leukemia: a meta-analysis. Medicine (Baltimore). (2019) 98:e16454. doi: 10.1097/MD.0000000000016454

63. Kinlen L. Evidence for an infective cause of childhood leukaemia: comparison of a Scottish new town with nuclear reprocessing sites in Britain. Lancet. (1988) 2:1323-7. doi: 10.1016/S0140-6736(88)90867-7

64. Greaves MF. Speculations on the cause of childhood acute lymphoblastic leukemia. Leukemia. (1988) 2:120-5.

65. Hauer J, Fischer U, Borkhardt A. Towards prevention of childhood ALL by early-life immune training. Blood. (2021) 138:1412-28. doi: 10.1182/blood.2020009895

66. Cobaleda C, Vicente-Duenas C, Sanchez-Garcia I. Infectious triggers and novel therapeutic opportunities in childhood B cell leukaemia. Nat Rev Immunol. (2021).

67. Greaves M, Cazzaniga V, Ford A. Can we prevent childhood Leukaemia? Leukemia. (2021) 35:1258-64. doi: 10.1038/s41375-021-01211-7

68. Kreis C, Doessegger E, Lupatsch JE, Spycher BD. Space-time clustering of childhood cancers: a systematic review and pooled analysis. Eur J Epidemiol. (2019) 34:9-21. doi: 10.1007/s10654-018-0456-y

69. Cazzaniga G, Bisanti L, Randi G, Deandrea S, Bungaro S, Pregliasco F, et al. Possible role of pandemic AH1N1 swine flu virus in a childhood leukemia cluster. Leukemia. (2017) 31:1819-21. doi: 10.1038/leu.2017.127 
70. Heath CW Jr, Hasterlik RJ. Leukemia among children in a suburban community. 1963. CA Cancer J Clin. (1990) 40:27-50. doi: 10.3322/canjclin.40.1.29

71. Francis SS, Selvin S, Yang W, Buffler PA, Wiemels JL. Unusual space-time patterning of the Fallon, Nevada leukemia cluster: Evidence of an infectious etiology. Chem Biol Interact. (2012) 196:102-9. doi: 10.1016/j.cbi.2011.02.019

72. Kroll ME, Draper GJ, Stiller CA, Murphy MF. Childhood leukemia incidence in Britain, 1974-2000: time trends and possible relation to influenza epidemics. J Natl Cancer Inst. (2006) 98:417-20. doi: 10.1093/jnci/djj095

73. Schmiedel S, Blettner M, Kaatsch P, Schuz J. Spatial clustering and spacetime clusters of leukemia among children in Germany, 1987-2007. Eur J Epidemiol. (2010) 25:627-33. doi: 10.1007/s10654-010-9488-7

74. Westermeier T, Michaelis J. Applicability of the Poisson distribution to model the data of the German Children's Cancer Registry. Radiat Environ Biophys. (1995) 34:7-11. doi: 10.1007/BF01210539

75. Kinlen LJ. An examination, with a meta-analysis, of studies of childhood leukaemia in relation to population mixing. Br J Cancer. (2012) 107:11638. doi: $10.1038 /$ bjc. 2012.402

76. Maia Rda R, Wunsch Filho V. Infection and childhood leukemia: review of evidence. Rev Saude Publica. (2013) 47:1172-85. doi: 10.1590/S0034-89102013000901172

77. He JR, Ramakrishnan R, Hirst JE, Bonaventure A, Francis SS, Paltiel $\mathrm{O}$, et al. Maternal infection in pregnancy and childhood leukemia: a systematic review and meta-analysis. J Pediatr. (2020) 217:98-109.e8. doi: 10.1016/j.jpeds.2019.10.046

78. He JR, Hirst JE, Tikellis G, Phillips GS, Ramakrishnan R, Paltiel O, et al. Common maternal infections during pregnancy and childhood leukaemia in the offspring: findings from six international birth cohorts. Int J Epidemiol. (2021). doi: 10.1093/ije/dyab199. [Epub ahead of print].

79. Martin-Lorenzo A, Hauer J, Vicente-Duenas C, Auer F, GonzalezHerrero I, Garcia-Ramirez I, et al. Infection exposure is a causal factor in B-cell precursor acute lymphoblastic leukemia as a result of Pax5-inherited susceptibility. Cancer Discov. (2015) 5:1328-43. doi: 10.1158/2159-8290.CD-15-0892

80. Rodriguez-Hernandez G, Opitz FV, Delgado P, Walter C, Alvarez-Prado AF, Gonzalez-Herrero I, et al. Infectious stimuli promote malignant B-cell acute lymphoblastic leukemia in the absence of AID. Nat Commun. (2019) 10:5563. doi: 10.1038/s41467-019-13570-y

81. Swaminathan S, Klemm L, Park E, Papaemmanuil E, Ford A, Kweon SM, et al. Mechanisms of clonal evolution in childhood acute lymphoblastic leukemia. Nat Immunol. (2015) 16:766-74. doi: 10.1038/ni.3160

82. Vicente-Duenas C, Janssen S, Oldenburg M, Auer F, GonzalezHerrero I, Casado-Garcia A, et al. An intact gut microbiome protects genetically predisposed mice against leukemia. Blood. (2020) 136:2003-17. doi: 10.1182/blood.2019004381

83. Abt MC, Artis D. The intestinal microbiota in health and disease: the influence of microbial products on immune cell homeostasis. Curr Opin Gastroenterol. (2009) 25:496-502. doi: 10.1097/MOG.0b013e328331b6b4

84. Beneforti L, Dander E, Bresolin S, Bueno C, Acunzo D, Bertagna M, et al. Pro-inflammatory cytokines favor the emergence of ETV6-RUNX1-positive pre-leukemic cells in a model of mesenchymal niche. Br J Haematol. (2020) 190:262-73. doi: 10.1111/bjh.16523

85. Lillie K. Leukaemia and lockdown: The delayed infection model of childhood acute lymphoblastic leukaemia and the COVID-19 pandemic. Pediatr Blood Cancer. (2021) 68:e29194. doi: 10.1002/pbc.29194

86. Richardson D, Sugiyama H, Nishi N, Sakata R, Shimizu Y, Grant EJ, et al. Ionizing radiation and leukemia mortality among Japanese Atomic Bomb Survivors, 1950-2000. Radiat Res. (2009) 172:368-82. doi: 10.1667/RR1801.1

87. UNSCEAR. Nations Scientific Committee on the Effects of Atomic Radiation 2013 Report, Sources, effects and risks of ionizing radiation, vol. II Annex $B$, Effects of radiation exposure of children. New York, NY: United Nations (2013)

88. Murray R, Heckel P, Hempelmann LH. Leukemia in children exposed to ionizing radiation. N Engl J Med. (1959) 261:5859. doi: 10.1056/NEJM195909172611203

89. Simpson CL, Hempelmann LH, Fuller LM. Neoplasia in children treated with X-rays in infancy for thymic enlargement. Radiology. (1955) 64:8405. doi: $10.1148 / 64.6 .840$
90. Kutanzi KR, Lumen A, Koturbash I, Miousse IR. Pediatric exposures to ionizing radiation: carcinogenic considerations. Int J Environ Res Public Health. (2016) 13:1057. doi: 10.3390/ijerph13111057

91. Hsu WL, Preston DL, Soda M, Sugiyama H, Funamoto S, Kodama $\mathrm{K}$, et al. The incidence of leukemia, lymphoma and multiple myeloma among atomic bomb survivors: 1950-2001. Radiat Res. (2013) 179:36182. doi: $10.1667 /$ RR2892.1

92. UNSCEAR. United Nations Scientific Committee on the Effects of Atomic Radiation (UNSCEAR) 2000 Report, Scientific Annex G: Biological Effects at Low Radiation Doses. New York: United Nations (2000).

93. UNSCEAR. Biological mechanisms of radiation actions at low doses. A white paper to guide the Scientific Committee's future programme of work. New York: United Nations (2012). Available online at: https://www.unscear.org/ docs/reports/Biological_mechanisms_WP_12-57831.pdf (accessed August 13, 2021).

94. Little MP, Wakeford R, Borrego D, French B, Zablotska LB, Adams $\mathrm{MJ}$, et al. Leukaemia and myeloid malignancy among people exposed to low doses $(<100 \mathrm{mSv})$ of ionising radiation during childhood: a pooled analysis of nine historical cohort studies. Lancet Haematol. (2018) 5:e346-e58. doi: 10.1016/S2352-3026(18)30 092-9

95. Abalo KD, Rage E, Leuraud K, Richardson DB, Le Pointe HD, Laurier D, et al. Early life ionizing radiation exposure and cancer risks: systematic review and meta-analysis. Pediatr Radiol. (2021) 51:4556. doi: 10.1007/s00247-020-04803-0

96. Baaken D, Hammer GP, Seidenbusch MC, Schneider K, Spix C, Blettner M, et al. Second follow-up of a German cohort on childhood cancer incidence after exposure to postnatal diagnostic x-ray. J Radiol Prot. (2019) 39:107491. doi: 10.1088/1361-6498/ab3506

97. Bollaerts K, Simons K, Van Bladel L, De Smedt T, Sonck M, Fierens $\mathrm{S}$, et al. Childhood leukaemia near nuclear sites in Belgium, 20022008. Eur J Cancer Prev. (2018) 27:184-91. doi: 10.1097/CEJ.00000000000 00272

98. UNSCEAR. United Nations Scientific Committee on the Effects of Atomic Radiation 2000 Report, Vol I. Annex B, Sources, Effects and Risks of Ionizing Radiation. New York, NY: United Nations (2000).

99. Mazzei-Abba A, Folly CL, Coste A, Wakeford R, Little MP, RaaschouNielsen O, et al. Epidemiological studies of natural sources of radiation and childhood cancer: current challenges and future perspectives. J Radiol Prot. (2019) 40:R1-R23. doi: 10.1088/1361-6498/ab5a38

100. Spycher BD, Lupatsch JE, Zwahlen M, Roosli M, Niggli F, Grotzer MA, et al. Background ionizing radiation and the risk of childhood cancer: a census-based nationwide cohort study. Environ Health Perspect. (2015) 123:622-8. doi: 10.1289/ehp.1408548

101. Mazzei-Abba A, Folly CL, Kreis C, Ammann RA, Adam C, Brack E, et al. External background ionizing radiation and childhood cancer: update of a nationwide cohort analysis. J Environ Radioact. (2021) 2389:106734. doi: 10.1016/j.jenvrad.2021.106734

102. Berlivet J, Hemon D, Clero E, Ielsch G, Laurier D, Faure L, et al. Residential exposure to natural background radiation at birth and risk of childhood acute leukemia in France, 1990-2009. J Environ Radioact. (2021) 233:106613. doi: 10.1016/j.jenvrad.2021.106613

103. Demoury C, Marquant F, Ielsch G, Goujon S, Debayle C, Faure L, et al. Residential exposure to natural background radiation and risk of childhood acute leukemia in France, 1990-2009. Environ Health Perspect. (2017) 125:714-20. doi: 10.1289/EHP296

104. Kendall GM, Little MP, Wakeford R, Bunch KJ, Miles JC, Vincent TJ, et al. A record-based case-control study of natural background radiation and the incidence of childhood leukaemia and other cancers in Great Britain during 1980-2006. Leukemia. (2013) 27:3-9. doi: 10.1038/leu.20 12.151

105. The United Kingdom Childhood Cancer Study: objectives, materials and methods. UK Childhood Cancer Study Investigators. Br J Cancer. (2000) 82:1073-102. doi: 10.1054/bjoc.1999.1045

106. Kendall GM, Wakeford R, Athanson M, Vincent TJ, Carter EJ, McColl NP, et al. Levels of naturally occurring gamma radiation measured in British homes and their prediction in particular residences. Radiat Environ Biophys. (2016) 55:103-24. doi: 10.1007/s00411-016-0635-8 
107. Chernyavskiy P, Kendall GM, Wakeford R, Little MP. Spatial prediction of naturally occurring gamma radiation in Great Britain. J Environ Radioact. (2016) 164:300-11. doi: 10.1016/j.jenvrad.2016.07.029

108. Kendall GM, Chernyavskiy P, Appleton JD, Miles JCH, Wakeford R, Athanson M, et al. Modelling the bimodal distribution of indoor gammaray dose-rates in Great Britain. Radiat Environ Biophys. (2018) 57:32147. doi: 10.1007/s00411-018-0752-7

109. Kendall GM, Little MP, Wakeford R. A review of studies of childhood cancer and natural background radiation. Int J Radiat Biol. (2021) 97:76981. doi: 10.1080/09553002.2020.1867926

110. Greenland S, Sheppard AR, Kaune WT, Poole C, Kelsh MA. A pooled analysis of magnetic fields, wire codes, and childhood leukemia Childhood Leukemia-EMF Study Group. Epidemiology. (2000) 11:62434. doi: 10.1097/00001648-200011000-00003

111. Kheifets L, Ahlbom A, Crespi CM, Draper G, Hagihara J, Lowenthal RM, et al. Pooled analysis of recent studies on magnetic fields and childhood leukaemia. Br J Cancer. (2010) 103:1128-35. doi: 10.1038/sj.bjc.6605838

112. Schuz J, Svendsen AL, Linet MS, McBride ML, Roman E, Feychting $\mathrm{M}$, et al. Nighttime exposure to electromagnetic fields and childhood leukemia: an extended pooled analysis. Am J Epidemiol. (2007) 166:2639. doi: 10.1093/aje/kwm080

113. Amoon AT, Crespi CM, Ahlbom A, Bhatnagar M, Bray I, Bunch $\mathrm{KJ}$, et al. Proximity to overhead power lines and childhood leukaemia: an international pooled analysis. Br J Cancer. (2018) 119:364-73. doi: 10.1038/s41416-018-0097-7

114. IARC. Non-ionizing radiation, Part 1: Static and extremely low-frequency (ELF) electric and magnetic fields. $<$ city $>$ Lyon $</$ city $>$, France: IARC Press (2002).

115. Swanson J, Kheifets L, Vergara X. Changes over time in the reported risk for childhood leukaemia and magnetic fields. J Radiol Prot. (2019) 39:47088. doi: 10.1088/1361-6498/ab0586

116. Amoon AT, Swanson J, Magnani C, Johansen C, Kheifets L. Pooled analysis of recent studies of magnetic fields and childhood leukemia. Environ Res. (2021) 204(Pt A):111993. doi: 10.1016/j.envres.2021.111993

117. Gajsek P, Ravazzani P, Grellier J, Samaras T, Bakos J, Thuroczy G. Review of Studies Concerning Electromagnetic Field (EMF) Exposure Assessment in Europe: low frequency fields $(50 \mathrm{~Hz}-100 \mathrm{kHz})$. Int J Environ Res Public Health. (2016) 13:875. doi: 10.3390/ijerph13090875

118. Schuz J. Implications from epidemiologic studies on magnetic fields and the risk of childhood leukemia on protection guidelines. Health Phys. (2007) 92:642-8. doi: 10.1097/01.HP.0000243154.46491.7d

119. Mezei G, Kheifets L. Selection bias and its implications for case-control studies: a case study of magnetic field exposure and childhood leukaemia. Int J Epidemiol. (2006) 35:397-406. doi: 10.1093/ije/dyi245

120. Scientific Committee on Emerging Newly Identified Health R. Opinion on potential health effects of exposure to electromagnetic fields. Bioelectromagnetics. (2015) 36:480-4. doi: 10.1002/bem.21930

121. WHO. Extremely Low Frequency Fields. Environmental Health Criteria 238. Geneva: World Health Organization (2007).

122. Li M, Jones L, Gaillard C, Binnewies M, Ochoa R, Garcia E, et al. Initially disadvantaged, TEL-AML1 cells expand and initiate leukemia in response to irradiation and cooperating mutations. Leukemia. (2013) 27:1570-3. doi: 10.1038/leu.2013.15

123. Jamrog L, Chemin G, Fregona V, Coster L, Pasquet M, Oudinet C, et al. PAX5-ELN oncoprotein promotes multistep B-cell acute lymphoblastic leukemia in mice. Proc Natl Acad Sci U S A. (2018) 115:1035762. doi: $10.1073 /$ pnas. 1721678115

124. Campos-Sanchez E, Vicente-Duenas C, Rodriguez-Hernandez G, Capstick M, Kuster N, Dasenbrock C, et al. Novel ETV6-RUNX1 mouse model to study the role of ELF-MF in childhood B-Acute lymphoblastic leukemia: a pilot study. Bioelectromagnetics. (2019) 40:343-53. doi: 10.1002/bem.22193

125. Schuz J, Dasenbrock C, Ravazzani P, Roosli M, Schar P, Bounds PL, et al. Extremely low-frequency magnetic fields and risk of childhood leukemia: a risk assessment by the ARIMMORA consortium. Bioelectromagnetics. (2016) 37:183-9. doi: 10.1002/bem.21963

126. Fu C, Jiang A. Dendritic Cells and CD8 T Cell Immunity in Tumor Microenvironment. Front Immunol. (2018) 9:3059. doi: $10.3389 /$ fimmu.2018.03059
127. Schuz J, Erdmann F. Environmental Exposure and Risk of Childhood Leukemia: An Overview. Arch Med Res. (2016) 47:607-14. doi: 10.1016/j.arcmed.2016.11.017

128. Hjalgrim LL, Westergaard T, Rostgaard K, Schmiegelow K, Melbye M, Hjalgrim $\mathrm{H}$, et al. Birth weight as a risk factor for childhood leukemia: a meta-analysis of 18 epidemiologic studies. Am J Epidemiol. (2003) 158:72435. doi: 10.1093/aje/kwg210

129. Linet MS, Brown LM, Mbulaiteye SM, Check D, Ostroumova E, Landgren A, et al. International long-term trends and recent patterns in the incidence of leukemias and lymphomas among children and adolescents ages $0-19$ years. Int J Cancer. (2016) 138:1862-74. doi: 10.1002/ijc.29924

130. Bailey HD, Infante-Rivard C, Metayer C, Clavel J, Lightfoot T, Kaatsch P, et al. Home pesticide exposures and risk of childhood leukemia: Findings from the childhood leukemia international consortium. Int J Cancer. (2015) 137:2644-63. doi: 10.1002/ijc.29631

131. Karalexi MA, Tagkas CF, Markozannes G, Tseretopoulou X, Hernandez AF, Schuz J, et al. Exposure to pesticides and childhood leukemia risk: a systematic review and meta-analysis. Environ Pollut. (2021) 285:117376. doi: 10.1016/j.envpol.2021.117376

132. Filippini T, Heck JE, Malagoli C, Del Giovane C, Vinceti M. A review and meta-analysis of outdoor air pollution and risk of childhood leukemia. J Environ Sci Health C Environ Carcinog Ecotoxicol Rev. (2015) 33:3666. doi: 10.1080/10590501.2015.1002999

133. Hvidtfeldt UA, Erdmann F, Urhoj SK, Brandt J, Geels C, Ketzel M, et al. Air pollution exposure at the residence and risk of childhood cancers in Denmark: a nationwide register-based case-control study. EClinicalMedicine. (2020) 28:100569. doi: 10.1016/j.eclinm.2020.100569

134. Mazzei A, Konstantinoudis G, Kreis C, Diezi M, Ammann RA, Zwahlen $\mathrm{M}$, et al. Childhood cancer and residential proximity to petrol stations: a nationwide registry-based case-control study in Switzerland and an updated meta-analysis. Int Arch Occup Environ Health. (2021). doi: 10.1007/s00420-021-01767-y. [Epub ahead of print].

135. Bailey HD, Metayer C, Milne E, Petridou ET, Infante-Rivard C, Spector LG, et al. Home paint exposures and risk of childhood acute lymphoblastic leukemia: findings from the Childhood Leukemia International Consortium. Cancer Causes Control. (2015) 26:1257-70. doi: 10.1007/s10552-015-0618-0

136. Liu R, Zhang L, McHale CM, Hammond SK. Paternal smoking and risk of childhood acute lymphoblastic leukemia: systematic review and metaanalysis. J Oncol. (2011) 2011:854584. doi: 10.1155/2011/854584

137. Cao Y, Lu J, Lu J. Paternal smoking before conception and during pregnancy is associated with an increased risk of childhood acute lymphoblastic leukemia: a systematic review and metaanalysis of 17 case-control studies. J Pediatr Hematol Oncol. (2020) 42:32-40. doi: 10.1097/MPH.0000000000001657

138. Marcotte EL, Thomopoulos TP, Infante-Rivard C, Clavel J, Petridou ET, Schuz J, et al. Caesarean delivery and risk of childhood leukaemia: a pooled analysis from the Childhood Leukemia International Consortium (CLIC). Lancet Haematol. (2016) 3:e176-85. doi: 10.1016/S2352-3026(16)00002-8

139. Wan Ismail WR, Abdul Rahman R, Rahman NAA, Atil A, Nawi AM. The protective effect of maternal folic acid supplementation on childhood cancer: a systematic review and meta-analysis of case-control studies. J Prev Med Public Health. (2019) 52:205-13. doi: 10.3961/jpmph.19.020

140. Rudant J, Lightfoot T, Urayama KY, Petridou E, Dockerty JD, Magnani $\mathrm{C}$, et al. Childhood acute lymphoblastic leukemia and indicators of early immune stimulation: a childhood leukemia international consortium study. Am J Epidemiol. (2015) 181:549-62. doi: 10.1093/aje/kw u298

Conflict of Interest: The authors declare that the research was conducted in the absence of any commercial or financial relationships that could be construed as a potential conflict of interest.

Publisher's Note: All claims expressed in this article are solely those of the authors and do not necessarily represent those of their affiliated organizations, or those of the publisher, the editors and the reviewers. Any product that may be evaluated in this article, or claim that may be made by its manufacturer, is not guaranteed or endorsed by the publisher. 
Copyright @ 2021 Schmidt, Hornhardt, Erdmann, Sánchez-García, Fischer, Schüz and Ziegelberger. This is an open-access article distributed under the terms of the Creative Commons Attribution License (CC BY). The use, distribution or reproduction in other forums is permitted, provided the original author(s) and the copyright owner(s) are credited and that the original publication in this journal is cited, in accordance with accepted academic practice. No use, distribution or reproduction is permitted which does not comply with these terms. 